\title{
Intergenerational Co-residence during later life in Europe and China
}

Tom Emery, Pearl Dykstra and Maja Djundeva

Erasmus University Rotterdam

Introduction

One of the most marked differences in family dynamics between China and Europe to which this special issue is dedicated is the prevalence of intergenerational co-residence. A high proportion of individuals live with their adult children in later life in China when compared with their European counterparts. This is often explained by the heightened familialism and filial piety evident within Chinese society, a suggestion that the culture of family is fundamentally distinct between Europe and China (Hamilton, 1990). Yet this assertion, that Chinese families and European families act as they do because they are Chinese and European, can be unsatisfying and potentially tautological, raising a significant number of questions about intergenerational co-residence in both Europe and China.

For example, Southern Europeans and Northern Europeans are often demarcated in terms of their familial values in much the same way as Chinese and Europeans. This raises the question of how familialism in Southern Europe specifically differs from familialism in China. Is it just stronger in China or is it fundamentally different? Similarly, in China intergenerational co-residence has been declining precipitately over the past quarter of a century. Is this decline a sign of convergence with European families and the emergence of modern family practices in the vein of William Goode, or are we to expect a persistent cultural difference between Chinese and European Societies? Arguments imbedded in cultural theories are challenged by such observations and undermine the view that European and Chinese societies are inherently distinct, incoherent and incomparable.

We argue that the fundamental difference in contemporary co-residence levels is instead attributable to the welfare state arrangements that individuals have access to. This position follows the tradition of European Comparative Welfare State literature by placing micro level dynamics within the context of welfare state support mechanisms. The implications of this position are considerable and suggest that the observed differences will likely be short lived as China's welfare state develops and Europe's continues on a path of retrenchment. It also suggests that Chinese and European family dynamics should not be considered as entirely distinct, but instead an opportunity to understand and identify the role of context.

We provide evidence in support of this by examining patterns of co-residence between parents and their adult children in Europe and China. We analyze parent-child dyads from the Survey for Health, Ageing and Retirement in Europe (SHARE) alongside data from the Chinese Family Panel Study (CFPS) in a multi-level framework that encapsulates dynamics at the family level and sub-regional level. We do so in order to answer a rather fundamental yet straight forward research question: why do Chinese parents co-reside with their children more than their European counterparts? The question is simple but the analyses are not given that complex family dynamics and diverse socioeconomic contexts need to be accounted for within the analysis. Our findings indicate the role of welfare institutions in shaping co-residence patterns both within and between Europe and China. In China, the extent and intensity of intergenerational support necessitates co-residence. In Europe by contrast, both upward care for elderly parents and downward care for grandchildren are only loosely associated with co-residence, and conducted with less intensity. This indicates that European familial care is auxiliary, even in Southern Europe, when compared with the high degree of interdependence in China. 


\section{Existing Research}

\section{Co-residence in Europe and China}

Cross-national variations in intergenerational co-residence have long been a topic of family sociology. Within this discussion there have broadly been two schools of thought. First, there are theories of economic development and modernization which suggest that varying socio-economic conditions largely explain the cross-national variability in co-residence. Second, there are arguments of cultural determinism which point to societal path dependency and family norms to explain why intergenerational co-residence remains prevalent in some countries and relatively rare in others. There are arguments that lie in between these, arguing that initial cultural differences are eroded by processes of modernization (Cheung \& Kwan, 2009), but the majority of research on co-residence see's the practice as culturally or economically based.

Functionalist perspectives from the American positivist tradition were the first to systematically examine cross-national variation in family composition and in so doing placed the emphasis on the role of economic forces in shaping individual's behavior. Large extended families were seen as the preserve of traditional societies and, with modernization, these would become redundant and the nuclear family would come to dominate (Goode, 1963). This process was said to be brought about by the need for greater mobility and independence within modern labor markets and the decreased interdependencies that came with a highly urbanized population. Empirical evidence in support of these arguments is mixed but broadly supports the general hypotheses that there is a link between economic development and co-residence.

For example, in the United States co-residence appears to decline in conjunction with economic development and urbanization (Hareven, 1994). Specifically, analysis from the US appears to indicate that intergenerational co-residence is eroded as an institution by the increased economic opportunities of the young and not by the development of social security (S. Ruggles, 2007). Empowered younger generations seeking new employment and educational opportunities have little incentive to continue co-residing with elderly parents and instead move out before marriage and maintain their independence through the life-course. This appears to be borne out by individual level research we shows co-residence being shaped by the needs of the child rather than those of the parent (Smits, van Gaalen, \& Mulder, 2010; Ward, Logan, \& Spitze, 1992).

Research specifically on Urban China and urban migrants specifically have gravitated towards these theories given the rapid and disruptive nature of economic development over the past 30 years $(Q$. F. Zhang, 2004). Here the emphasis is also on the increased opportunities afforded to younger generations with parents left to lament the loss of co-residence as an institution (Logan \& Bian, 1999). This is typified by urban migrants who leave intergenerational co-residence in urban areas to purse the economic opportunities in urban areas, maintaining intergenerational relations through remittances to elderly parents rather than co-residence (Chen, Leeson, \& Liu, 2016). Yet further scrutiny of the situation in China appears to raise questions as to whether modernity is actually the eroding intergenerational co-residence. For example, intergenerational co-residence is seen to be associated with female labor supply rather than counter to it (Goh, 2009; Shen, Yan, \& Zeng, 2016) and co-residing parents often elect to live with the most educated child rather than lowest educated child so as to facilitate their labor market participation (Wen \& Hanley, 2015). In contrast to the US, the child's needs appear to require co-residence for economic success rather than be an impingement of it, undermining the rational that modernization is counter to intergenerational coresidence. 
Culture theories of family formation offer an alternative understanding of intergenerational coresidence and have often been used to explain variations between Europe and East Asia (Hajnal, 1982). Such theories tend to assert that family structure and behaviours are deeply imbedded in the political economy of a society and through institutional path dependency, reflect themselves in contemporary norms and practices even when modernization processes displace traditional social institutions. Broadly speaking, Western Europeans are traditionally have an older age of first marriage which is preceded by a period of residence independent of the family (Reher, 1998). This weakens long term ties with family members and reduces co-residence later in the life-course. Such theories are supported by sticky co-residence levels that do not converge across developed and otherwise similar economies (Glaser, Tomassini, \& Grundy, 2004; Steven Ruggles \& Heggeness, 2008).

Cultural theories of co-residence fit well with Chinese perspectives on the family given the Confucian tradition of filial piety. Filial piety is widely seen as a key demarcating factor between Chinese and European families even to the extent that differences in co-residence can be observed in Asian migrants long after their arrival in Western countries (Kamo \& Zhou, 1994). The set of values encompassed by the Confucian understanding of filial piety have been used to explain several features of intergenerational relations that appear to be unique to East Asian societies (Hamilton, 1990). Filial piety values are higher in East Asian societies and associated with greater probability of co-residence (Z. Zhang, Gu, \& Luo, 2014). Specifically, co-residence tends to be patrilineal with a strong tendency to co-reside with sons and not daughters (Zhan \& Montgomery, 2003) and there is greater support from child to parent than is observed in European or American analysis (Guo, Chi, \& Silverstein, 2012).

Despite these cultural particularities, there is still evidence that modernization is changing parentchild relations in China and that this at least redefining filial piety if not eroding it (Cheung \& Kwan, 2009; Chu, Xie, \& Yu, 2011; Emery, Dykstra, \& Djundeva, 2016). Co-residence in urban areas is lower and the gender dynamics are distinct from rural areas and Confucian traditions (Whyte \& Xu, 2003; Xie \& Zhu, 2009). There is therefore a gap within the literature. Co-residence dynamics in China have been well explored and documented through modernization and cultural perspectives. However, there is not a coherent answer to the question of why co-residence differs so greatly from what has been observed in Europe. Is it modernization and so we can expect greater convergence, or is it a cultural difference which will be evident even as levels of economic development converge? In this analysis we employ European welfare state theories to help understand what differentiates Chinese families from their European counterparts and the extent to which both culture and economic development contribute to family dynamics.

\section{Theory \& Hypotheses}

In this paper we extend the theory of European Welfare Regimes to the context of Chinese Society in order to explore and examine intergenerational co-residence in China and Europe. European Welfare Regime Typologies are grounded heavily in the historical socio-economic context of European societies with a specific focus on the institutionalization of cultural norms and resulting path dependency (Esping-Andersen, 1990). These have been then adapted and realigned to reflect specific areas of policy, especially policies relating to gender and family relations (Lewis, 1992). The result of this process has been the identification of four broad types of welfare state in the field of family policy.

In Conservative welfare states there remains the primacy of the wage earner and strong familisation tendencies by which family members, and women in particular, are implicitly assumed to adopt 
caring roles. This has softened in recent years in a number of countries with the extension of policies such as childcare subsidies but the core dynamics of highly gendered care-giving remain. In such instances the role of the welfare state is to support the care role of women and not to replace it. These welfare state arrangements are typically attributed to countries of Western and Central Europe such as France, Germany, the Netherlands and Austria but the tradition of familisation is even more intense in Southern and Eastern Europe where public care provision is very limited and state support for care-providers in the form of well-paid leave is also weaker.

In Nordic countries, welfare state arrangements adopt a contrasting logic by which the wage earning role of all individuals is supported. This is referred to as defamilisation in that the care of both children and elderly relatives is largely individualized through the welfare state. These welfare state arrangements are marked by short but well paid leave for both mothers and fathers, extensive and accessible childcare provision, a generous state pension and extensive and high quality care provision for those in old age in need of care.

Given the complex array of social policies that these typologies represent there are considerable deviations from these two ideal types. For example, In Western Europe there is better childcare provision than in Central Europe which alleviates work-life conflicts for mothers. Similarly in Central Europe, pension arrangements are relatively strong and thus place less emphasis on familial responsibility in later life. This contrasts strongly with Eastern Europe where the pension is less mature and replacement rates are far lower, raising the implicit care burden for other family members. Liberal-Welfare states also adopt a more gender neutral stance with regards to care provision but are far weaker in the provision of public alternatives, instead focusing on private sector alternatives. However, in this analysis we do not have data from liberal welfare states and they do not form part of our hypotheses.

These welfare state theories have been extended to East Asian societies and China in particular on numerous occasions with East Asian welfare states being identified as Productivist Welfare States (Holliday, 2000). Within such welfare states the primary aim is economic and political stability rather than the protection of specific rights. So whilst European welfare states have aimed to ensure that individuals receive care and support either through the family (familisation) or through public provision (defamilialisation), East Asian welfare states have been primarily concerned with the stabilizing effects of the welfare state in political and economic terms.

In practice this has meant the creation of welfare arrangements in sectors identified of specific economic or political concern. For example, state employees have access to relatively generous pension arrangements in order to ensure a degree of political stability. Similarly, certain sectors have specific social security arrangements to insulate the economy from large economic shocks such as the Asian Financial Crisis of 1997 or the Global Economic Crisis of 2008. The result is a sharp 'insideroutsider' dynamic by which some sub-sections of society are able to access state supported pension arrangements and facilities and others are not. In China, this arrangement also encompasses the hukou household registration system which affectively demarcates the urban population into 'urban residents' and 'migrant workers' with the latter group receiving different, and almost always worse, welfare arrangements. This system ensures that urban governments and their welfare systems are not overwhelmed by the demand brought about by the influx of migrants but can still benefit from the increase in labor supply.

The result of productivist welfare state policies is therefore that 'urban residents', 'migrants' and 'rural residents' face very different welfare arrangements and subsequently different family dynamics with regards to care provision. Urban Chinese have access to public facilities that their 
compatriots do not and in particular childcare, schools, hospitals and care facilities. The growing middle class within China has led to increasing demands for improved facilities and the result has been a relative explosion in the number of such facilities in urban areas over the past 20 years (See figure X). Similarly, pension provisions amongst Urban Chinese are far more established and developed which reduces dependencies in old age. Nevertheless, Urban Chinese are not better off in every way and care related leave remains virtually non-existent.

The situation of migrants is very distinct from urban residents despite their geographic proximity. Not only are they regularly denied access to schools, childcare, hospitals and care facilities that the urban residents have access to, they are also excluded from public programs that can help negate the need for care arising such as public housing schemes and adequate pension programs. Yet the primary rational of being a migrant is to seek better wage employment and so there is a strong emphasis on full employment within migrant households. Strong gender roles would undermine this rational and this leaves a care deficit within migrant families, as neither the state nor women are able or willing to provide care. Despite their dislocation from their rural roots, it is found that migrants are therefore highly dependent on their family for welfare support either by having them co-reside in the urban area or through complex care arrangements which span their physical divide such as children residing with their rural grandparents.

In rural areas there is also exceptionally limited public provision both in terms of public facilities but also broader social policies such as pensions, parental leave arrangements and public housing. The family unit is however far more active and central in care provision. Amongst rural residents, $\mathrm{X} \%$ are involved in farm production. Care provision therefore becomes a more integral part of the household economy as is the case in more traditional societies. The result is that all welfare needs are met by the family within a singular household. These three circumstances for urban residents, migrants and rural residents in China therefore lead to differing family dynamics in terms of care provision and co-residence and it is this that provides the hypotheses for this paper.

We supplement these welfare state theories with a basic rational choice perspective on intergenerational relations (Altonji, Hayashi, \& Kotlikof, 1995). From this we suggest that, in the absence of public provision of welfare, parents choose to co-reside with those they think will best support them in later life. This means that they are more likely to co-reside with sons as they believe that they will be placed to take care of them later in life regarding housing and income. The less public support there is, the greater the incentive of investing in adult son's family units during the formative years of later life. Parents will also invest more heavily in those who are high achieving. The better a child's labor market returns are, the more likely that they will be in a position to support their parents in later life. Given this, we suggest that parent's without access to welfare state arrangements such as pensions, housing and care facilities, will engage in exchange based behavior by which they co-reside with the child which they believe will be best placed to care for them and provide support to that child so as to both maximize that child's success and develop a reciprocal obligation with the child. Based on this theory we therefore anticipate that:

H1a: Parents in Southern and Eastern Europe will be more likely to co-reside with a child than Central and Western Europeans and Scandinavians

We assert that the base level of co-residence in Scandinavia and Central and Western Europe is lower than in Southern and Eastern Europe given that both pension provision and the public care sector are more developed in the former than the latter. This leads to greater dependency in later life and an increased tendency to co-reside. 
H1b: Migrant Parents in China will be more likely to co-reside with a child than Urban and Rural Chinese

In China we believe that the base level of co-residence will be highest amongst migrant populations, somewhat lower amongst rural populations and lowest in urban areas. This is because pension policy amongst migrant populations is exceptionally low and individuals fall between rural and urban welfare arrangements leading too low to non-existent provisions. In rural areas there are limited and relatively recent pension provisions that somewhat alleviate the dependency of Older Chinese and we thus expect co-residence to be somewhat lower. However amongst the urban population both public care facilities and pensions reduce dependency amongst elderly populations.

H2a: Migrant and Rural Parents in China will be more likely to co-reside with their higher educated children than their lower educated children

In the absence of adequate pension provision and policy support, we anticipate that parents will choose to co-reside with the highest educated child. This is because they anticipate that this child will have the highest economic returns from the labor market and will be the most likely to provide support in the future. The parent's co-residence not only strengthens the relationship and interdependency with this child but also potentially increases labor market productivity through the provision of grandparental care and general household production.

H2b: Parents in Europe and Urban China will be as likely to co-reside with their lower educated children as their higher educated children

With the provision of pensions, dependence on children is lower in later life. Instead welfare state provisions should level the playing field between children and we would not expect to see an educational gradient in the co-residence of parents with their adult children.

H3: Parents in China and Europe are more likely to reside with their sons than their daughters

From a gender perspective we anticipate that co-residence will be predominantly with sons given that in both China and Europe, men's lifetime earnings are greater than women's. Parents will therefore look to co-reside with their sons as they are more likely to be in a strong economic position when they, the parent, enters later life.

H4a: Parents in Central, Southern and Eastern Europe will be relatively more likely to coreside with their sons than Western Europeans and Scandinavians

The incentive to invest in the male over the female is however dependent on the degree to which the labor market is favorable towards women. In countries where women are able to combine work and family life and maintain contact with the labor market, the difference in co-residence between men and women will be lesser. Based on the existing literature we would therefore expect the gender differential in co-residence to be lowest in Scandinavia and Western Europe.

H4b: Parents in rural china and migrant parents will be relatively more likely to co-reside with their sons than Urban Chinese

With regards to China, the gender differential will be most pronounced amongst rural and migrant populations. This is because, according to existing findings, the labor market outcomes in these populations remain highly gendered and men are therefore a more stable prospect for co-residence and dependency in later life. In Urban China, where women are more able to maintain labor market activity, we would expect a much diminished differential in gender preference of co-residence. This hypotheses is key in differentiating welfare state and rational choice theories with theories of 
cultural practice. If elderly Chinese have adapted their practices of patrilinealism in response to the improved prospects of women on the labor market, this would suggest that it was a rational choice decision rather than cultural inertia that was leading to the previously observed son preference.

\section{Data \& Methods}

The data used in our analysis is from the Survey for Health, Ageing and Retirement in Europe (SHARE) and the Chinese Family Panel Studies (CFPS). The data from SHARE is taken from the $5^{\text {th }}$ wave with fieldwork completed in 2012 and the data from the CFPS is taken from the $1^{\text {st }}$ wave which was fielded in 2010. The data from both countries was then restricted to respondents aged over 60 at the time of interview as questions in the CFPS used for the analysis were only fielded to this subpopulation. In both surveys, respondents were asked a series of questions about each of their living children. These responses were then used to reshape the data into a file of parent-child dyads. Throughout the analysis we adopt a multilevel framework with these dyads (Level 1) nested within individual respondents (Level 2). To this end, childless respondents are excluded from the analysis.

The main dependent variable is a dichotomous indicator of whether the respondent co-resides with the specific child to which the dyad corresponds at the time of the interview. Co-residence was taken to be inclusive of parents and children who lived in the same physical building but excluded 'financial households' as defined in the CFPS which shared financial arrangements but lived in physically separate spaces. A set of controls in the form of age, sex, marital status and education level were then created for both the parent and child. The total number of children of the respondent was also included as a control at the parental level and birth order at the dyadic level. Education was coded based on ISCED classifications where anything below completion of secondary education (ISCED $0,1,2$ ) is considered 'Low Education', the completion of secondary education is considered 'Medium Education' (ISCED 3 and 4) and completion of any education beyond secondary education is considered 'High Education' (ISCED 5, 6, 7). This scale was maintained for the parental generation in the CFPS despite the distribution being wholly uneven and dominated by the 'Low Educated' (59.32\%).

In addition to these basic controls indicators of two vectors of intergenerational care and exchange were included; the giving of grandparental childcare to the children of that specific child and the receipt of personal care from that specific child. These indicators are constructed differently across the two surveys. In SHARE the indicator is a composite of SP005_ and SP021d_ which measure care received from individuals outside of the household and care received from individuals inside the household respectively. If a respondent indicated that they either received care from these individuals at least once a month or they were co-resident with someone they identified as a care giver then they were coded as being in receipt of care. The distinction between residents and nonresidents doesn't exist for the variables regarding care for grandchildren and thus variable SP016 was used. For the CFPS, the variable qf3_s_41 - qf3_s_60 were used and enabled respondents to simply indicate whether they had received personal care from a specific child in the past 6 months or not and whether they had provided childcare to the children of this child or not in the last 6 months.

There are serious issues of whether these indicators are directly comparable and given the difference in wording and construction we are skeptical as to whether they measure precisely the same concepts of care and childcare. However we decided to include these indicators for the following reasons. First, the two datasets are analyzed separately with distinct coefficients and so they do not contribute to the same statistical estimates. Secondly, we use care giving only as control which allows for a better understanding of some of the underlying dynamics of co-residence rather than as the main independent variable. Nevertheless, it is important to note the differences 
between these variables in order to dissuade direct comparisons between these indicators in the models.

In order to capture the key concept of welfare state variations we adopted differing strategies in Europe and China which reflect common research practices and traditions. In Europe we split the sample into welfare regimes representing the aforementioned clustering of social policies around specific typologies. Austria, Germany and Switzerland were considered Central European, France, the Netherlands and Belgium were considered Western European, Denmark and Sweden represent Scandinavia, Italy, Greece, Spain and Portugal represent Southern Europe and Croatia, Czechia, Hungary, Slovenia, Poland and Estonia represent Eastern Europe. Israel and Ireland were omitted from the analysis as they fit into welfare state typologies that are not part of our analysis. In China, the population was segregated, not geographically but by using their household registration status (hukou). Those respondents resident in a rural area were considered rural, those with a rural hukou but living in an urban area were considered migrants and those with an urban hukou were considered hukou. These categories broadly reflect the position of respondents relative to welfare services available to them.

After listwise deletion of missing values and the aforementioned sample constraints we were left with a workable sample of 5,020 in China and 33,879 in Europe with 14,089 and 81,169 parent-child dyads respectively. The number of missings and the resulting sample is presented in Table 1. Calibrated cross-sectional design weights were applied to both samples to ensure national representativeness. In the Chinese data it should be noted that only 30 of 36 provinces were covered by the sampling due to logistical and political constraints but this still covers more than $95 \%$ of the Chinese population. In order to examine co-residence dynamics in China and Europe, three separate iterations of a multilevel logistic regression model were constructed for both the SHARE and CFPS data. The first models represent a basic model of co-residence between parent and children with the key independent variables of the child's gender and education included. The second and third models are then interacted with welfare regime categorization in SHARE and the respondent's hukou status in the CFPS in order to test the remaining hypotheses.

\section{Results}

The initial results of our analysis are very much supportive of what is found in the existing literature from both Europe and China. This is best illustrated by the findings regarding our first hypotheses which suggests that parents in Scandinavia and Central and Western Europe are less likely to coreside with a child than in Southern and Eastern Europe. This is indeed what we find as can be seen from table $x$. Looking at the descriptives alone we can see that $4.53 \%$ of parents over 60 in Scandinavia, $7.53 \%$ of those in Central Europe and $6.44 \%$ of those in Western Europe reside with their children. This contrasts strongly however with the $13.8 \%$ in Southern Europe who choose to coreside with their parents. In China we see that $26.0 \%$ of migrant parents over 60 are living with their adult children. This is higher than both the $21.3 \%$ of rural parents and the $17.1 \%$ of urban parents who do so. This supports the assertion of hypotheses $1 \mathrm{~b}$ and indicates that the levels of co-residence are not uniform across China.

In model 2 we see the interaction between child's educational level and the welfare regime or hukou status. Amongst rural and migrant parents in China we can see that in support of hypotheses 2a, parents do tend to co-reside with higher educated children. There is a clear and distinct positive gradient in these two subpopulations that contrasts strongly with the urban population. However, amongst the urban Chinese population we do not see a null gradient of the child's educational level but instead a clear and consistent negative gradient which would appear to indicate that parents are 
opting to co-reside with lower educated children. However, whilst this is not in line with the hypothesis, it is worth noting that is consistent across Europe and Urban China suggesting a potential commonality in co-residence dynamics.

In model 3 we see the interaction between child's gender and the welfare regime or hukou status. The results from model 1 had indicated that hypotheses 3 was indeed correct in so much that the preference for co-residence with sons is universal. However, as figures $X \& X$ indicate, there is a great deal of variation in the differential across the various sub-populations. In Europe the gradient is significantly larger in Central and Southern Europe than elsewhere. However this is not the case for Eastern Europe. Hypotheses $4 a$ is therefore partially supported in that two of the three most genderized welfare states had the highest gender differential in co-residence. In China, we see from figure $X$ that there is a very large gender differential in co-residence as is found in the existing literature. However, this gender differential is significantly smaller in urban China and thus we find strong evidence in support of hypotheses $4 \mathrm{~b}$.

\section{Discussion \& Conclusions}

The results provide strong support for the hypotheses with two notable exceptions. First, the gender differential for co-residence in Eastern Europe is not statistically significantly different from that observed in Western Europe. This could indicate that either our conceptionalisation of Eastern Europe as a gender inegalitarian labor market or Western Europe as a gender egalitarian labor market are wrong. Indeed, part of the legacy of socialism in Eastern Europe is that there is a degree of gender equality in labor market outcomes that is not found in more conservative parts of Europe such as the Centre and South. Similarly, gender egalitarianism in Western Europe is still short of the Nordic Welfare State. For example, in the Netherlands female employment is largely driven by parttime employment (Plantenga, 2002) and maternal employment remains relatively low in France (Gornick, Meyers, \& Ross, 1997). Conversely, it could simply be that there are other factors beyond labor market gender inequality that is driving the preference for sons. For example, cultural values are highly associated but lagged from welfare state arrangements and it is highly plausible that the welfare state is only one vector through which these cultural values shape the co-residence patterns of Europeans. However, we find similar patterns in China and they appear to suggest that areas where there is greater support for female employment have lower preference for son co-residence.

The second exception is the observation that the educational gradient of co-residence is in fact negative and not nil in Europe and Urban China. This is somewhat perplexing as it is unclear as to why parents may opt to live with the least educated child. The obvious answer is that these children have less resources and therefore have greater needs than their more educated siblings. This would suggest that the intergenerational dynamics switch being from one of exchange and intergenerational exchange to one of altruism and downward support as the welfare state develops to provide for those in later life. One potential complication to this theory is that the development of a welfare state usually occurs across policy areas and so increases in pension provisions is usually coupled with increases in support for younger generations such as employment insurance, social housing and health insurance which would alleviate the need for co-residence. We remain unconvinced by the evidence that we have looked at given the limited information on the child within the data. Future research could have investigate this further by examining such co-residence from a child perspective.

Beyond these two exceptions we found strong evidence for welfare states shaping the co-residence patterns of Chinese and European parents over 60 . The results not only support welfare state based theories but also indicate that alternatives are unlikely to explain the findings equally as well. For 
example, we found that not only is there a gender preference for residing with sons in China but that this weakened amongst elderly parents but was highest amongst migrants. Cultural theories of coresidence which suggest that this is driven by norms of filial piety are poor in explaining why those Chinese who move to cities might be more inclined to follow such norms when compared to those in rural areas. This patterning is therefore supportive of a welfare state narrative rather than a cultural description, as migrant populations become trapped between urban and rural welfare arrangements. Furthermore, if cultural norms are driving the preference for sons then this mechanism should be assumed to be weak as it is a much smaller preference amongst urban populations.

In Europe we also see complex patterning that is not supported by simple cultural narratives. Welfare state theories suggest that the pension and care provisions for the elderly within a country should drive the base level of co-residence where as the gender inegalitarianism in the labor market drives the gender differential. This is supported by what we find in Central Europe when compared to Western Europe. In both we have strong pensions and so see a low level of co-residence with adult children. However, in Central Europe the labor market is less gender egalitarian and so we see a more pronounced gender differential in co-residence as parents tend to opt to live with the son when they do look to co-reside with children. Theories of economic development and modernization would similarly indicate that co-residence amongst urban individuals would be lower than rural areas but these fail to account for the unique position of migrants in China. Cultural norms or theories of economic development, to the best of the author's knowledge, cannot be used to explain both the similar base level of co-residence and the contrasting gender differentials for these areas.

We therefore conclude that the difference in co-residence rates between China and Europe are not largely cultural or economic but instead driven by differing welfare state contexts as has been argued in the existing European literature. Indeed, when we look at urban China when the Chinese welfare state is most developed we see strong parallels with European societies and comparable rates of co-residence. We would therefore anticipate that recent reforms in China which soften the boundaries between urban and rural hukou and increase welfare provisions in rural areas will lead to further convergence in rates of co-residence. This has serious implications in a country that is ageing rapidly and will soon have a population structure similar to that in Europe as it should not be assumed that intergenerational co-residence will remain the norm.

To further test this propostion we would therefore urge further research in the role of policy in shaping intergenerational family dynamics in China. There are a large number of natural experiments that can be observed in China as municipal authorities loosen the restrictions on migrants accessing urban services and there is a keen and prescient demand for understanding how policy shapes family relations in China given the rapid developments in the composition of the population and the policy environment in which they find themselves. However, researchers assessing the role of policy in China can look to a rich and established field of research in Europe where the role of welfare policies has been conceptualized and examined in considerable detail. 


\section{Bibliography}

Altonji, J. G., Hayashi, F., \& Kotlikof, L. J. (1995). Parental Altruism and Inter Vivos: Transfers Theory and Evidence.

Chen, T., Leeson, G. W., \& Liu, C. (2016). Living arrangements and intergenerational monetary transfers of older Chinese. Ageing and Society, 1-26. http://doi.org/10.1017/S0144686X16000623

Cheung, C.-K., \& Kwan, A. Y.-H. (2009). The erosion of filial piety by modernisation in Chinese cities. Ageing and Society, 29(2), 179-198. http://doi.org/10.1017/S0144686X08007836

Chu, C. Y. C., Xie, Y., \& Yu, R. R. (2011). Coresidence with elderly parents: A comparative study of Southeast China and Taiwan. Journal of Marriage and Family, 73(1), 120-135. http://doi.org/10.1111/j.1741-3737.2010.00793.x

Emery, T., Dykstra, P., \& Djundeva, M. (2016). Chinese Parent-Child Relationships in Later Life Running Title: Chinese Parent-Child Relationships in Later Life.

Esping-Andersen, G. (1990). The Three World of Welfare Capitalism. Princeton, NJ: Princeton University Press.

Glaser, K., Tomassini, C., \& Grundy, E. (2004). Revisiting convergence and divergence: support for older people in Europe. European Journal of Ageing, 1(1), 64-72. http://doi.org/10.1007/s10433-004-0006-1

Goh, E. C. L. (2009). Grandparents as childcare providers: An in-depth analysis of the case of Xiamen, China. Journal of Aging Studies, 23(1), 60-68. http://doi.org/10.1016/j.jaging.2007.08.001

Goode, W. J. (1963). World revolution and family patterns. Oxford: Free Press.

Gornick, J. C., Meyers, M. K., \& Ross, K. E. (1997). Supporting the Employment of Mothers : Policy Defining employment-supporting policies. Journal of European Social Policy, 7(1), 45-70.

Guo, M., Chi, I., \& Silverstein, M. (2012). The Structure of Intergenerational Relations in Rural China: A Latent Class Analysis. Journal of Marriage and Family, 74(October), 1114-1128. http://doi.org/10.1111/j.1741-3737.2012.01014.x

Hajnal, J. (1982). Two Kinds of Preindustrial Household Formation System. Population and Development Review, 8(3), 449-494.

Hamilton, G. G. (1990). Patriarchy, Patrimonialism, and Filial Piety: A Comparison of China and Western Europe \n. The British JournalofSociology, 41(1), 77-104. http://doi.org/10.2307/591019

Hareven, T. K. (1994). Aging and Generational Relations : A Historical and Life Course Perspective. Annual Review of Sociology, 20, 437-461.

Holliday, I. (2000). Productivist welfare capitalism: Social policy in East Asia. Political Studies, 48, 706-723. http://doi.org/10.1111/1467-9248.00279

Kamo, Y., \& Zhou, M. (1994). Living arrangements of elderly Chinese and Japanese in the United States. Journal of Marriage and the Family, 56(3), 544-558.

Lewis, J. (1992). Gender and the Development of Welfare Regimes. Journal of European Social Policy, 2(3), 159-173.

Logan, J. R. ., \& Bian, F. (1999). Family Values and Coresidence with Married Children in Urban China. Social Forces, 77(4), 1253-1282. 
Plantenga, J. (2002). Combining work and care in the polder model: an assessment of the Dutch parttime strategy. Critical Social Policy, 22(1), 53-71.

http://doi.org/10.1177/02610183020220010601

Reher, D. S. (1998). Family Ties in Western Europe: Persistent Contrasts. Population and Development Review, 24(2), 203-234.

Ruggles, S. (2007). The Decline of Intergenerational Coresidence in the United States, 1850 to 2000. American Sociological Review, 72(6), 964-989. http://doi.org/10.1177/000312240707200606

Ruggles, S., \& Heggeness, M. (2008). Intergenerational coresidence in developing countries. Population and Development Review, 34(2), 253-281. http://doi.org/10.1111/j.17284457.2008.00219.x

Shen, K., Yan, P., \& Zeng, Y. (2016). Coresidence with elderly parents and female labor supply in China. Demographic Research, 35(September), 645-670. http://doi.org/10.4054/DemRes.2016.35.23

Smits, A., van Gaalen, R. I., \& Mulder, C. H. (2010). Parent-child coresidence: Who moves in with whom and for whose needs? Journal of Marriage and Family, 72(4), 1022-1033. http://doi.org/10.1111/j.1741-3737.2010.00746.x

Ward, R., Logan, J., \& Spitze, G. (1992). The Influence of Parent and Child Needs on Coresidence in Middle and Later Life. Journal of Marriage and Family, 54(1), 209-221.

Wen, Y., \& Hanley, J. (2015). Rural-to-Urban Migration, Family Resilience, and Policy Framework for Social Support in China. Asian Social Work and Policy Review, 9(1), 18-28. http://doi.org/10.1111/aswp.12042

Whyte, M. K., \& Xu, Q. (2003). Support for aging parents from daughters versus sons. In China's revolutions and intergenerational relations (pp. 167-196).

Xie, Y., \& Zhu, H. (2009). Do sons or daughters give more money to parents in urban China? Journal of Marriage and Family, 71(1), 174-186. http://doi.org/10.1111/j.1741-3737.2008.00588.x

Zhan, H. J., \& Montgomery, R. J. V. (2003). Gender And Elder Care In China: The Influence of Filial Piety and Structural Constraints. Gender \& Society, 17(2), 209-229. http://doi.org/10.1177/0891243202250734

Zhang, Q. F. (2004). Economic transition and new patterns of parent-adult child coresidence in urban China. Journal of Marriage and Family, 66(5), 1231-1245. http://doi.org/10.1111/j.00222445.2004.00089.x

Zhang, Z., Gu, D., \& Luo, Y. (2014). Coresidence With Elderly Parents in Contemporary China: The Role of Filial Piety, Reciprocity, Socioeconomic Resources, and Parental Needs. Journal of CrossCultural Gerontology, 29(3), 259-276. http://doi.org/10.1007/s10823-014-9239-4 
Table 1 - Multilevel Logit Models of Co-residence in Europe and China

\begin{tabular}{|c|c|c|c|c|c|}
\hline & \multicolumn{2}{|c|}{ Europe } & \multicolumn{2}{|c|}{ China } \\
\hline & & 1 & 2 & 3 & 4 \\
\hline \multirow[t]{4}{*}{ Parent } & Age & $1.063^{* * *}$ & $1.063^{* * *}$ & $1.087^{* * *}$ & $1.084^{* * *}$ \\
\hline & & $(0.007)$ & $(0.007)$ & (0.009) & $(0.009)$ \\
\hline & Number of Children & $0.826^{* * *}$ & $0.832 * * *$ & $0.515 * * *$ & $0.519 * * *$ \\
\hline & & $(0.020)$ & $(0.020)$ & $(0.015)$ & $(0.015)$ \\
\hline \multirow[t]{6}{*}{ Education } & Low & 1.000 & 1.000 & 1.000 & 1.000 \\
\hline & & (.) & (.) & (.) & (.) \\
\hline & Medium & $0.732 * * *$ & $0.724^{* * *}$ & 0.889 & 0.900 \\
\hline & & $(0.058)$ & $(0.057)$ & $(0.068)$ & $(0.068)$ \\
\hline & High & $0.663 * * *$ & $0.659 * * *$ & $0.514^{* *}$ & $0.565 *$ \\
\hline & & $(0.058)$ & $(0.057)$ & $(0.115)$ & $(0.128)$ \\
\hline \multirow[t]{4}{*}{ Gender } & Male & 1.000 & 1.000 & 1.000 & 1.000 \\
\hline & & (.) & (.) & $()$. & (.) \\
\hline & Female & $1.720 * * *$ & $1.719 * * *$ & $1.211 * *$ & $1.213^{* *}$ \\
\hline & & (0.109) & (0.108) & $(0.087)$ & $(0.087)$ \\
\hline \multirow[t]{4}{*}{ Marital Status } & Married & 1.000 & 1.000 & 1.000 & 1.000 \\
\hline & & $()$. & (.) & (.) & (.) \\
\hline & Not Married & $3.884 * * *$ & $3.870 * * *$ & $2.066 * * *$ & $2.041 * * *$ \\
\hline & & $(0.271)$ & $(0.268)$ & $(0.177)$ & $(0.172)$ \\
\hline \multirow[t]{2}{*}{ Child } & Age & $0.861 * * *$ & $0.863 * * *$ & $0.920 * * *$ & $0.923 * * *$ \\
\hline & & $(0.005)$ & $(0.005)$ & $(0.006)$ & $(0.006)$ \\
\hline \multirow[t]{6}{*}{ Education } & Low & 1.000 & 1.000 & 1.000 & 1.000 \\
\hline & & (.) & (.) & (.) & (.) \\
\hline & Medium & $0.762 * * *$ & 0.973 & 0.875 & 0.927 \\
\hline & & $(0.055)$ & $(0.122)$ & $(0.086)$ & $(0.100)$ \\
\hline & High & $0.304 * * *$ & $0.412 * * *$ & $0.570 * * *$ & 1.595 \\
\hline & & $(0.026)$ & $(0.057)$ & $(0.082)$ & $(0.535)$ \\
\hline \multirow[t]{8}{*}{ Gender } & Male & 1.000 & 1.000 & 1.000 & 1.000 \\
\hline & & (.) & (.) & (.) & (.) \\
\hline & Female & $0.725 * * *$ & $0.628 * * *$ & $0.063 * * *$ & $0.122 * * *$ \\
\hline & & $(0.071)$ & $(0.033)$ & $(0.009)$ & $(0.011)$ \\
\hline & Married & 1.000 & 1.000 & 1.000 & 1.000 \\
\hline & & $()$. & (.) & $()$. & (.) \\
\hline & Not Married & $0.163 * * *$ & $0.166^{* * *}$ & $9.304 * * *$ & $9.485 * * *$ \\
\hline & & $(0.013)$ & $(0.013)$ & $(0.973)$ & (0.989) \\
\hline \multirow[t]{10}{*}{ Welfare Regime } & Western & 1.000 & 1.000 & & \\
\hline & & (.) & (.) & & \\
\hline & Scandinavian & $0.259 * * *$ & $0.550 * * *$ & & \\
\hline & & $(0.031)$ & $(0.096)$ & & \\
\hline & Central & $1.431 * * *$ & $1.921 * * *$ & & \\
\hline & & $(0.152)$ & $(0.331)$ & & \\
\hline & Southern & $4.310 * * *$ & $3.997 * * *$ & & \\
\hline & & $(0.596)$ & $(0.676)$ & & \\
\hline & Eastern & $3.277^{* * *}$ & $2.591 * * *$ & & \\
\hline & & $(0.394)$ & (0.587) & & \\
\hline \multirow[t]{13}{*}{ Hukou Status } & Rural & & & 1.000 & 1.000 \\
\hline & & & & (.) & (.) \\
\hline & Migrant & & & $1.226 *$ & 0.864 \\
\hline & & & & $(0.127)$ & $(0.228)$ \\
\hline & Urban & & & $0.411 * * *$ & 1.347 \\
\hline & & & & (0.039) & $(0.407)$ \\
\hline & Constant & 0.586 & $0.475 *$ & $0.184^{* * *}$ & $0.151 * * *$ \\
\hline & & $(0.179)$ & $(0.148)$ & $(0.087)$ & $(0.071)$ \\
\hline & $\operatorname{var}\left(\_\operatorname{cons}[\sim)\right.$ & $10.502^{* * *}$ & $9.847^{* * *}$ & $3.105^{* * *}$ & $2.853^{* * *}$ \\
\hline & & $(2.209)$ & $(2.038)$ & $(0.581)$ & $(0.514)$ \\
\hline & $\mathrm{N}$ & 23927 & 23927 & 13631 & 13631 \\
\hline & Log Likelihood & -7800.69 & -7782.86 & -4727.64 & -4735.4 \\
\hline & AIC & 15647.37 & 15619.72 & 9493.286 & 9512.799 \\
\hline
\end{tabular}

Note: Interaction effects are not shown and can be seen in figures $x-x$. 


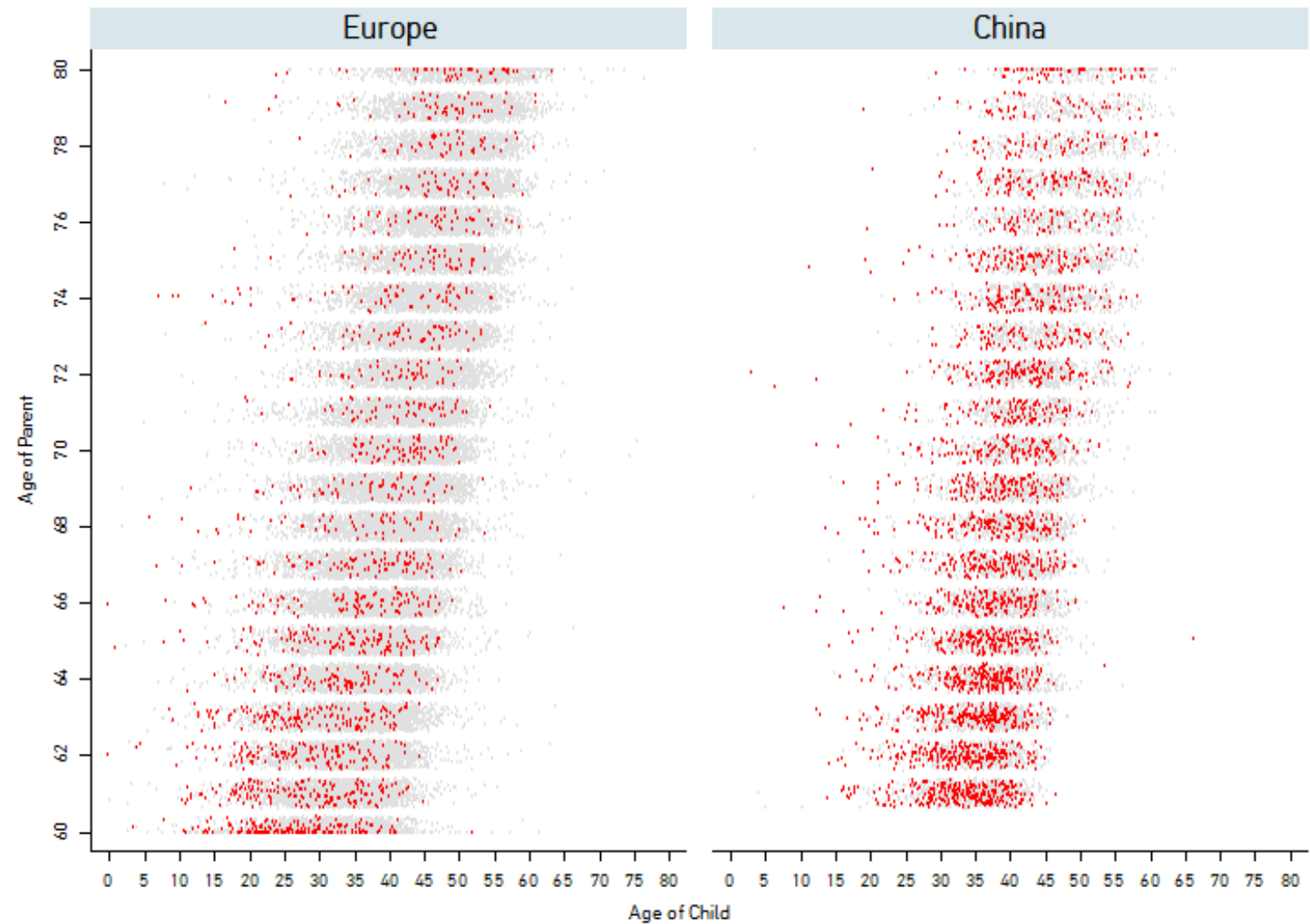

Figure 1 - Parent-Child Dyads and the prevalence of Co-residence in Europe and China [Red = Co-residence; Grey = Non-Coresident] 


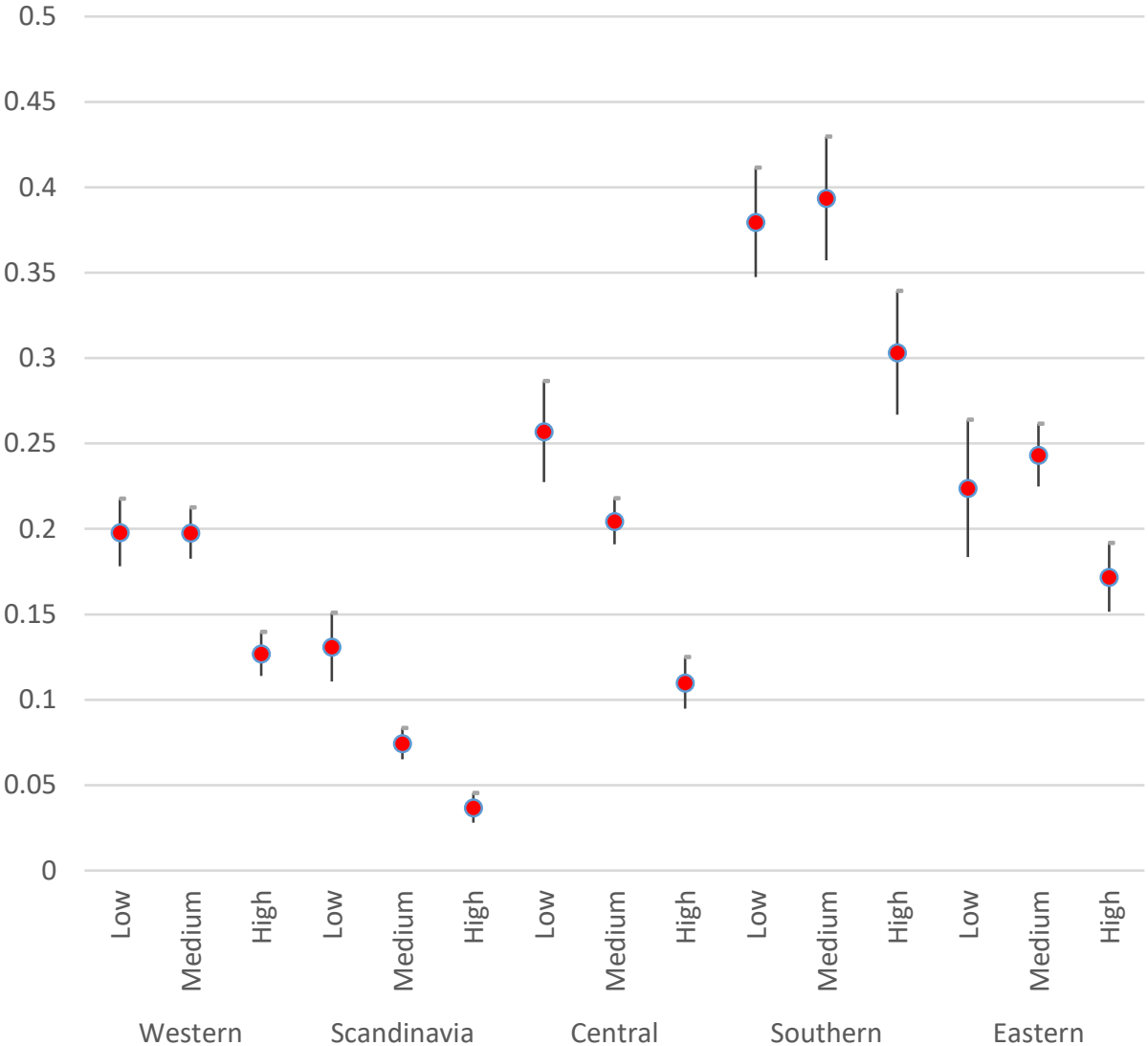

Figure 2 - Co-residence and the Child's Education Level in European Welfare State Regimes

0.7
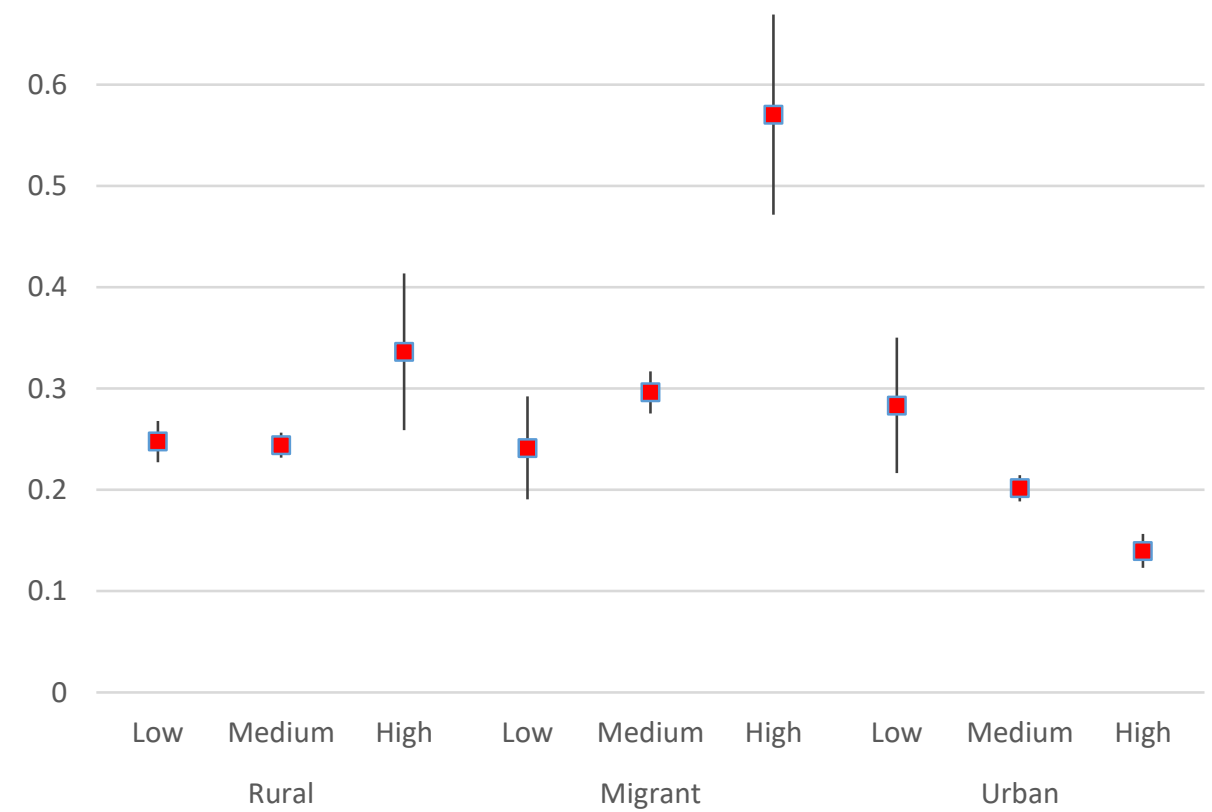

Figure 3-Co-residence and the Child's Education Level amongst the Chinese Elderly 
0.45

0.4

0.35

0.3

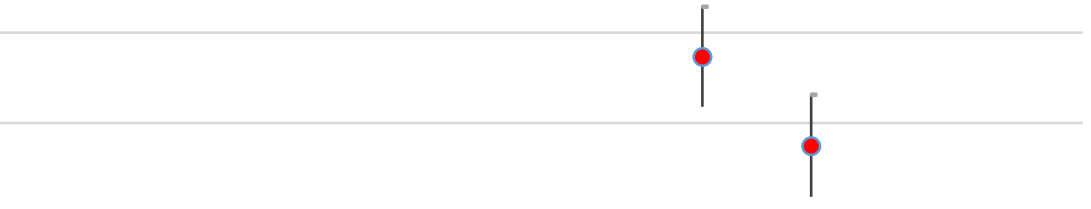

0.25

0.2

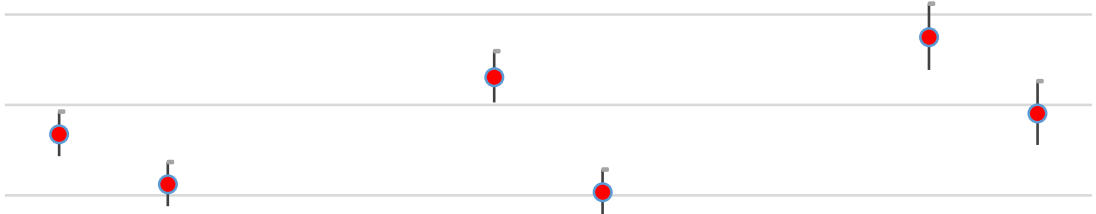

0.1

0.05

0

Male Female Male Female Male Female Male Female Male Female Western Scandinavia Central Southern Eastern

Figure 4-Co-residence and Gender of the Child in European Welfare Regimes

0.5

0.45

0.4

0.35

0.3

0.25

0.2

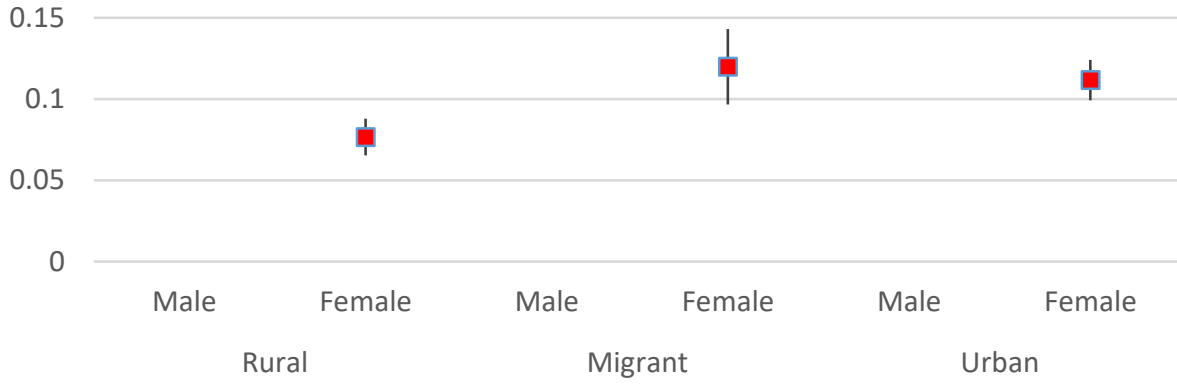

Figure 5 - Co-residence and Gender of the Child Amongst Chinese Elderly 